\title{
A PESQUISA EM LINGUAGEM, TECNOLOGIA E ENSINO DE LÍNGUA INGLESA NA REGIÃO NORTE DO BRASIL: IMPLICAÇÕES PARA A FORMAÇÃO DE PROFESSORES
}

\section{RESEARCH ON LANGUAGE, TECHNOLOGY AND ENGLISH LANGUAGE TEACHING IN THE NORTHERN REGION OF BRAZIL: IMPLICATIONS FOR TEACHER EDUCATION}

Ana Carolina Nascimento Souza Pinto Universidade Federal de Minas Gerais, Brasil ana.carolina.nsp@gmail.com

Vera Lúcia Menezes de Oliveira e Paiva Universidade Federal de Minas Gerais, Brasil vlmop@veramenezes.com

RESUMO: Este artigo apresenta uma metapesquisa sobre teses e dissertações sobre linguagem, tecnologia e uso de ferramentas digitais no ensino de língua inglesa, produzidas em programas de pós-graduação da Região Norte do Brasil. O objetivo principal é oferecer um panorama desse tipo de pesquisa nos últimos dez anos. Os dados foram coletados em plataformas digitais de pesquisa de teses e dissertações e foram encontradas apenas seis dissertações de mestrado. Analisamos os objetivos, as metodologias adotadas, bem como, os resultados apontados em cada trabalho. As pesquisas se baseiam predominantemente em estudos de caso, tendo como objeto de pesquisa um grupo específico de alunos e de professores de instituições educacionais da região. O texto reflete sobre questões particulares da Região Norte do Brasil e defende a necessidade de formação de professores para o uso de tecnologias digitais.

PALAVRAS-CHAVE: metapesquisa; linguagem e tecnologia; ensino e aprendizagem de inglês; formação de professor.

ABSTRACT: This article presents a meta-research report about theses and dissertations on language and technology and the use of digital tools in English language teaching, produced by graduate programs in the northern region of Brazil. The main objective is to provide an overview of this kind of research in the last ten years. Data were collected in digital research platforms for theses and dissertations. Only six M.A. studies were found. We analyzed the objectives, the methodologies adopted, as well as the results indicated in each study. The studies are predominantly based on case studies, with a specific group of students and teachers from educational institutions in the region. The text reflects on particular issues in the northern region of Brazil and defends the need of training teachers for the use of digital technologies.

KEYWORDS: meta-research; language and technology; English teaching and learning; teacher education. 


\section{Introdução}

Este relato de pesquisa faz parte de um projeto maior, intitulado "Lalintec: um ecossistema de produção e divulgação de pesquisas em linguagem e tecnologia", financiado pelo CNPq, edital universal 2016, projeto 404661/2016-5, coordenado pela segunda autora. O objetivo geral do projeto é "produzir, explorar e difundir novos conhecimentos sobre linguagem e tecnologia e ferramentas digitais na aprendizagem de inglês" no Brasil. Já os objetivos específicos do trabalho desenvolvido incluem: (a) buscar informações sobre pesquisa em linguagem e tecnologia no Brasil e detectar temas mais e menos pesquisados em programas de pós-graduação em Letras e Linguística de determinada região do país; (b) criar um catálogo de pesquisas em Linguagem e Tecnologia; (c) fazer curadoria de ferramentas e aplicativos digitais para o ensino de línguas.

Desse modo, o Lalintec tem como finalidade a criação de um banco de dados sobre tecnologia e ensino de línguas. Esse banco de pesquisas visa (a) promover a interação entre pesquisadores; (b) criar um espaço propício à inovação, a partir da combinação dos conhecimentos existentes sobre o assunto; (c) fornecer dados para novas pesquisas sobre o tema; (d) fomentar a reflexão sobre ensino-aprendizagem no atual contexto tecnológico em que vivemos. Dentro dessa proposta, para se obter um retrato geral dos estudos produzidos no Brasil sobre linguagem e tecnologia no ensino de inglês, foram feitas metapesquisas - pesquisas sobre pesquisas - sobre as cinco regiões brasileiras. Coube a nós investigar a Região Norte.

\subsection{A região norte}

A Região Norte é a mais extensa do Brasil e inclui sete estados: Acre, Amapá, Amazonas, Pará, Rondônia, Roraima e Tocantins. De acordo com dados disponíveis nas páginas do Instituto Brasileiro de Geografia e Estatística (IBGE), a área total da região é de $3.853 .840,882 \mathrm{~km}^{2}$, o equivalente a $45 \%$ dos $8.515 .759,090 \mathrm{~km}^{2}$ do território brasileiro. Por outro lado, possui a menor densidade demográfica, cerca de 4 hab. $/ \mathrm{km}^{2}$, equivalente a 8\% da população nacional. As bases econômicas dessa região são o extrativismo mineral e vegetal e a agricultura. Há, também, polos industriais, com destaque para a Zona Franca de Manaus.

Dotada de notável diversidade natural e sociocultural, abarcando comunidades urbanas, rurais, ribeirinhas, indígenas e quilombolas, essa região apresenta disparidades e contrastes. Bento et al. a descreve em duas dimensões:

de um lado o destaque dado à rica diversidade humana, dispersa num vasto território repleto de recursos naturais, e de outro a constatação da imensa desigualdade econômica e social que contrasta com as demais regiões do Brasil, bem como com as riquezas naturais da própria região (BENTO et al., 2013, p. 144).

Tais disparidades são justificadas por razões históricas e geopolíticas. Desde o século XVI, o território atraiu investimentos direcionados à exploração da terra e dos 
saberes de seus habitantes. Em contrapartida, foram poucas as iniciativas voltadas à educação e ao desenvolvimento científico. Como exposto por Nonato e Pereira,

para compreender a ciência na Região Norte do Brasil, é importante considerar a sua estreita relação com os objetivos geopolíticos e de exploração de recursos naturais da floresta amazônica, bem como o relacionamento com as comunidades tradicionais (NONATO; PEREIRA, 2013, p. 94).

Segundo Nonato e Pereira (2013, p. 114), somente na década de 1950 e 1960, a Região Norte recebeu suas primeiras universidades federais: a Universidade Federal do Pará (UFPA) e a Universidade Federal do Amazonas (UFAM), que foram instaladas em 1957 e 1962, respectivamente. Os mesmos autores informam que, a partir da década de 60, emergiram iniciativas para a descentralização. Em 1971 foi criada a Universidade Federal do Acre (UFAC). Posteriormente, surgiram a Universidade Federal de Rondônia, em 1981; a Universidade Federal de Roraima, em 1989; a Universidade Federal do Amapá, em 1990; e a Universidade Federal do Tocantins, em 2000.

A pós-graduação teve, portanto, um início relativamente tardio nessa localidade em relação às outras regiões do Brasil. De acordo com o relatório da Capes (2017a), publicado em 2017, o Norte concentra somente 5\% dos programas de pós-graduação brasileiros. A oferta é, portanto, consideravelmente pequena para a região.

Especificamente em relação à área de Letras, o relatório da Avaliação Quadrienal 2017 - Documento de Área - Letras e Linguística (BRASIL, 2017, p. 3) apontou que houve uma grande expansão dos programas de pós-graduação nos últimos anos. Ainda assim, a Região Norte possui o menor número de programas de pesquisa do Brasil e o estado do Amapá é o único no país que não conta com um programa de pós-graduação na área de Letras e Linguística.

A seguir, para que o leitor tenha uma visão global das informações sobre os programas nessa região, apresentamos uma síntese no Quadro 1.

Quadro 1: Programas de Pós-Graduação em Linguística e Literatura da Região Norte.

\begin{tabular}{|c|c|c|c|c|c|}
\hline Instituição & $\begin{array}{l}\text { Número de } \\
\text { Programas }\end{array}$ & $\begin{array}{l}\text { Nome do } \\
\text { Programa }\end{array}$ & $\begin{array}{l}\text { Área de } \\
\text { concentração }\end{array}$ & $\begin{array}{l}\text { Linhas de } \\
\text { Pesquisa }\end{array}$ & $\begin{array}{c}\text { Avaliaçãa } \\
\text { Capes } 2017\end{array}$ \\
\hline \multirow{3}{*}{$\begin{array}{l}\text { Universidad } \\
\text { e do Estado } \\
\text { do } \\
\text { Amazonas } \\
\text { (UEA) }\end{array}$} & \multirow{3}{*}{2} & \multirow{3}{*}{$\begin{array}{l}\text { Mestrado e } \\
\text { Mestrado } \\
\text { Profissional } \\
\text { Letras e } \\
\text { Artes }\end{array}$} & \multirow{3}{*}{$\begin{array}{l}\text { Representação } \\
\text { e interpretação } \\
\text { artística, } \\
\text { literária e } \\
\text { linguística }\end{array}$} & $\begin{array}{l}\text { Arquivo, memória e } \\
\text { interpretação }\end{array}$ & \multirow{3}{*}{3} \\
\hline & & & & $\begin{array}{l}\text { Linguagem, } \\
\text { Discurso e práticas } \\
\text { sociais } \\
\end{array}$ & \\
\hline & & & & \begin{tabular}{|l|} 
Teoria, crítica e \\
processos de \\
criação
\end{tabular} & \\
\hline \multirow{2}{*}{$\begin{array}{l}\text { Universidad } \\
\text { e Federal do } \\
\text { Acre (UFAC) }\end{array}$} & \multirow{2}{*}{1} & \multirow{2}{*}{$\begin{array}{l}\text { Mestrado } \\
\text { Letras - } \\
\text { Linguagem e } \\
\text { identidade }\end{array}$} & \multirow{2}{*}{$\begin{array}{l}\text { Linguagem e } \\
\text { Cultura }\end{array}$} & $\begin{array}{l}\text { Língua(gens) e } \\
\text { Formação Docente }\end{array}$ & \multirow{2}{*}{4} \\
\hline & & & & $\begin{array}{l}\text { Culturas, Narrativas } \\
\text { e Identidades }\end{array}$ & \\
\hline
\end{tabular}




\begin{tabular}{|c|c|c|c|c|c|}
\hline \multirow{5}{*}{$\begin{array}{l}\text { Universidad } \\
\text { e Federal do } \\
\text { Amazonas } \\
\text { (UFAM) }\end{array}$} & \multirow{5}{*}{1} & \multirow{5}{*}{$\begin{array}{l}\text { Mestrado } \\
\text { Letras }\end{array}$} & \multirow[t]{2}{*}{$\begin{array}{l}\text { Estudos } \\
\text { Literários }\end{array}$} & \begin{tabular}{|l} 
- Literatura, cultura \\
e \\
transdisciplinaridad \\
e
\end{tabular} & \multirow{5}{*}{3} \\
\hline & & & & $\begin{array}{l}\text { - Literatura e outras } \\
\text { linguagens }\end{array}$ & \\
\hline & & & \multirow{3}{*}{$\begin{array}{l}\text { Teoria e Análise } \\
\text { Linguística }\end{array}$} & $\begin{array}{l}\text { - Sociolinguística / } \\
\text { Dialectologia }\end{array}$ & \\
\hline & & & & $\begin{array}{l}\text { - Linguística } \\
\text { Aplicada }\end{array}$ & \\
\hline & & & & $\begin{array}{l}\text { - Análise do } \\
\text { Discurso }\end{array}$ & \\
\hline \multirow{7}{*}{$\begin{array}{l}\text { Universidad } \\
\text { e Federal do } \\
\text { Pará (UFPA) }\end{array}$} & \multirow{7}{*}{3} & \multirow{4}{*}{$\begin{array}{l}\text { Mestrado e } \\
\text { Doutorado } \\
\text { Letras: } \\
\text { Linguística e } \\
\text { teoria } \\
\text { literária }\end{array}$} & \multirow{2}{*}{$\begin{array}{l}\text { Estudos } \\
\text { Literários }\end{array}$} & $\begin{array}{l}\text {-Literatura: } \\
\text { interpretação, } \\
\text { circulação e } \\
\text { recepção } \\
\end{array}$ & \multirow{7}{*}{3} \\
\hline & & & & \begin{tabular}{|l}
-Literatura, \\
Memórias e \\
Identidades
\end{tabular} & \\
\hline & & & \multirow{2}{*}{$\begin{array}{l}\text { Estudos } \\
\text { Linguísticos }\end{array}$} & $\begin{array}{l}\text {-Análise, descrição } \\
\text { e documentação } \\
\text { das Línguas } \\
\text { naturais }\end{array}$ & \\
\hline & & & & $\begin{array}{l}\text {-Ensino- } \\
\text { aprendizagem de } \\
\text { Línguas e Culturas: } \\
\text { modelos e ações }\end{array}$ & \\
\hline & & \multirow{3}{*}{$\begin{array}{l}\text { Mestrado } \\
\text { Linguagens } \\
\text { e saberes na } \\
\text { Amazônia }\end{array}$} & \multirow{3}{*}{$\begin{array}{l}\text { Linguagens e } \\
\text { saberes }\end{array}$} & \begin{tabular}{|l} 
Leitura e Tradução \\
Cultural \\
\end{tabular} & \\
\hline & & & & \begin{tabular}{|l} 
Memórias e \\
Saberes \\
Interculturais
\end{tabular} & \\
\hline & & & & $\begin{array}{l}\text { Educação, Cultura e } \\
\text { Sociedade }\end{array}$ & \\
\hline \multirow{2}{*}{$\begin{array}{l}\text { Universidad } \\
\text { e Federal de } \\
\text { Roraima } \\
\text { (UFRR) }\end{array}$} & \multirow{2}{*}{1} & \multirow{2}{*}{$\begin{array}{l}\text { Mestrado } \\
\text { Letras }\end{array}$} & \multirow{2}{*}{$\begin{array}{l}\text { Estudos de } \\
\text { Linguagem e } \\
\text { Cultura } \\
\text { Regional }\end{array}$} & $\begin{array}{l}\text { Língua e Cultura } \\
\text { Regional }\end{array}$ & \multirow{2}{*}{3} \\
\hline & & & & \begin{tabular}{|l} 
Literatura, Artes e \\
Cultura Regional \\
\end{tabular} & \\
\hline \multirow{3}{*}{$\begin{array}{l}\text { Universidad } \\
\text { e Federal do } \\
\text { Tocantins } \\
\text { (UFT) }\end{array}$} & \multirow[t]{3}{*}{3} & \multirow{3}{*}{\begin{tabular}{|l} 
Mestrado e \\
Doutorado \\
Letras: \\
Ensino de \\
língua e \\
literatura
\end{tabular}} & \multirow[t]{3}{*}{$\begin{array}{l}\text { Ensino e } \\
\text { formação de } \\
\text { professores }\end{array}$} & $\begin{array}{l}\text { Linguagem, } \\
\text { educação e } \\
\text { diversidade cultural } \\
\end{array}$ & \multirow[t]{3}{*}{4} \\
\hline & & & & \begin{tabular}{|l|} 
Literatura, memória \\
e identidade cultural \\
em contextos de \\
formação \\
\end{tabular} & \\
\hline & & & & $\begin{array}{l}\text { Práticas discursivas } \\
\text { em contextos de } \\
\text { formação }\end{array}$ & \\
\hline
\end{tabular}




\begin{tabular}{|c|c|c|c|c|c|}
\hline & & & & \begin{tabular}{|l} 
Teoria e análise \\
linguística em \\
contextos de \\
formação \\
\end{tabular} & \\
\hline & & \multirow{4}{*}{$\begin{array}{l}\text { Mestrado } \\
\text { Letras }\end{array}$} & \multirow{2}{*}{$\begin{array}{l}\text { Estudos } \\
\text { Literários }\end{array}$} & $\begin{array}{l}\text { Literatura, História e } \\
\text { Imaginário }\end{array}$ & \multirow{4}{*}{3} \\
\hline & & & & \begin{tabular}{|l|} 
Teoria e Crítica \\
Literária Literatura \\
Comparada \\
\end{tabular} & \\
\hline & & & \multirow{2}{*}{$\begin{array}{l}\text { Estudos } \\
\text { Linguísticos }\end{array}$} & $\begin{array}{l}\text { Abordagens de } \\
\text { Análise Linguística }\end{array}$ & \\
\hline & & & & Linguística Aplicada & \\
\hline \multirow{4}{*}{$\begin{array}{l}\text { Universidad } \\
\text { e Federal de } \\
\text { Rondônia } \\
\text { (UNIR) }\end{array}$} & \multirow{4}{*}{2} & \multirow[t]{2}{*}{$\begin{array}{l}\text { Mestrado } \\
\text { Letras }\end{array}$} & \multirow{2}{*}{$\begin{array}{l}\text { Línguas, } \\
\text { Linguagens e } \\
\text { Culturas } \\
\text { Amazônicas }\end{array}$} & \begin{tabular}{|l|} 
Estudos descritivos \\
e aplicados de \\
Línguas e \\
Linguagens
\end{tabular} & \multirow{4}{*}{3} \\
\hline & & & & $\begin{array}{l}\text { Estudos de } \\
\text { diversidade cultural }\end{array}$ & \\
\hline & & \multirow{2}{*}{$\begin{array}{l}\text { Mestrado } \\
\text { Estudos } \\
\text { Literários }\end{array}$} & \multirow{2}{*}{$\begin{array}{l}\text { Estudos } \\
\text { Literários }\end{array}$} & $\begin{array}{l}\text { Literatura, teoria e } \\
\text { crítica }\end{array}$ & \\
\hline & & & & $\begin{array}{l}\text { Literatura, outros } \\
\text { saberes e outras } \\
\text { artes }\end{array}$ & \\
\hline
\end{tabular}

Fonte: elaborado pelas autoras.

Conforme destacado no relatório de avaliação quadrienal da Capes (2017b), entre os anos de 2000 e 2015 houve um intenso crescimento no número de programas de pósgraduação na área de Linguística e Literatura. Tal processo resultou na desconcentração do eixo Sudeste e no considerável aumento do número de programas na Região Norte do Brasil. Em 2000, a região contava apenas com um programa e, em 2015, passou a contar com 13. Portanto, a grande maioria dos programas existentes nessa localidade é muito recente e foram, em sua maior parte, criados entre os anos de 2010 e 2013. O mais recente deles é o curso de mestrado em Letras da Universidade Federal do Tocantins, em Porto Nacional, aprovado pela Capes em 2015.

Embora o processo de criação dos programas seja recente, este tem sido também intenso. Ao analisarmos as grades curriculares oferecidas, as inúmeras linhas de pesquisa e áreas de concentração já desenvolvidas em cada programa, são evidentes o esforço e o empenho para a formação de cursos de qualidade que atendam às necessidades dessa região com a criação de linhas de pesquisa voltadas para as questões culturais e de linguagem regionais,

O Quadro 1 revela que há certa uniformidade nas notas atribuídas pela Capes. Das sete universidades avaliadas, cinco conquistaram nota 3 - nota atribuída a programas criados recentemente, o que indica um desempenho médio, com padrões mínimos de qualidade - e duas delas alcançaram nota 4, indicando um bom desempenho dos programas oferecidos pela Universidade Federal do Acre (UFAC) e pela Universidade Federal do Tocantins (UFT). 
É notável o especial interesse em linhas de pesquisa voltadas à interdisciplinaridade - como o mestrado profissional em Letras e Artes, oferecido pela Universidade do Estado do Amazonas (UEA) - e à valorização da cultura local - como o Mestrado em Linguagens e saberes na Amazônia, oferecido pela Universidade Federal do Pará (UFPA); os Estudos de Linguagem e Cultura Regional, oferecidos pela Universidade Federal de Roraima (UFRR); e a área de Línguas, Linguagens e Culturas Amazônicas, oferecida pela Universidade Federal de Rondônia (UNIR).

Vale destacar a preocupação das Universidades com as carências de sua localidade, conforme apresentado nas páginas virtuais dos programas de pós-graduação pesquisados. A página do Programa de Pós-Graduação em Letras da Universidade Federal de Tocantins salienta que "o curso de mestrado do Programa de Pós-Graduação em Letras da UFT em Porto Nacional foi criado devido à carência de recursos humanos altamente qualificados nas áreas de Letras e Linguística na região centro-sul do Estado do Tocantins". Os mesmos propósitos são ressaltados, também, na página do Programa de Pós-Graduação em Letras e Artes da Universidade Estadual do Amazonas:

Ao que se refere à inserção do Programa na região Norte, ele vem a suprir uma demanda de anos, em toda a região [...] a inserção do PPGLA - Programa de PósGraduação em Letras e Artes - na região tem trazido resultados positivos, dentre os quais destacamos a formação local de profissionais, em especial para atuarem nas universidades e faculdades do estado, sobretudo para a formação de docentes concursados que ainda não possuem mestrado.

É importante sublinhar que essa mesma atenção às necessidades e às particularidades da região também é perceptível nos estudos elencados e analisados neste artigo.

\section{Metodologia}

Esta pesquisa se caracteriza como uma metapesquisa ou meta-análise. Como os nomes já dizem, é uma pesquisa sobre pesquisa ou uma análise sobre a análise. Ela consiste em fazer uma análise estatística de relatos de pesquisa sobre um determinado assunto de forma a fornecer um panorama e comparar alguns aspectos do que foi produzido em determinado período.

Trochim, Donnelly e Arora (2016) afirmam que "uma meta-análise é sempre uma síntese quantitativa" (p. 7) que definem como "[U]m tipo de síntese de pesquisa que utiliza métodos estatísticos para combinar os resultados de estudos semelhantes quantitativamente de forma a permitir que se façam conclusões gerais". Já Perry (2017, p. 141) define meta-análise como "[U]m método de pesquisa que analisa resultados qualitativos e quantitativos de um número de estudos individuais com um propósito de integrar os achados". Como o autor adverte, esse tipo de pesquisa não deve ser confundida com revisão de literatura, pois "são pesquisas primárias que usam outros estudos como dados" (p. 141) e cujo objetivo principal é estabelecer uma comparação entre esses estudos.

No nosso caso, usamos dados numéricos simples, verificamos quais foram os 
temas investigados, os objetivos, a metodologia e os resultados descritos nas dissertações produzidas na Região Norte e disponíveis nas páginas dos programas da web.

Para a coleta dos dados foi utilizada a Plataforma Sucupira da Capes e as páginas na web dos programas de pós-graduação da Região Norte, durante os anos de 2017 e 2018.

A pesquisa seguiu os passos aconselhados por Walliman (2011, p. 90):

1. Definição dos tipos de tese e dissertação que seriam incluídos na pesquisa. Selecionamos apenas as investigações voltadas para o ensino de inglês e que usavam a tecnologia de alguma forma.

2. Coleta dos dados de acordo com os temas definidos. Foram localizados trabalhos sobre a temática em questão na Plataforma Sucupira da Capes, onde foram também identificados quais eram os programas de pós-graduação da Região Norte. Em seguida, visitamos as páginas de cada programa para localizar os demais estudos a serem analisados.

3. Seleção de um método para investigar as variáveis para detectar relações significantes. Optou-se pela leitura dos resumos, dos objetivos e das seções de metodologia e dos resultados. Foram selecionados estudos cujos objetivos e resultados pautavam-se especificamente na análise e/ou aplicação de recurso(s) tecnológico(s) no ensino da língua inglesa. Não foram consideradas pesquisas que fizeram menção ao tema de forma meramente pontual, sem contemplá-lo em seus objetivos.

4. Selecionar o propósito da análise dos dados dos resultados, uma comparação para detectar o quanto os resultados dos estudos variavam, ou para acompanhar uma variável específica em todos os estudos e acumular os resultados para indicar sua importância. Foi construído um quadro com os trabalhos selecionados e, em seguida, foi feita uma descrição sucinta de cada trabalho e apresentados os objetivos de cada um, a metodologia e os resultados.

O último passo foi relatar os resultados, discutir as limitações da pesquisa e fazer recomendações para pesquisa futura.

\section{A metapesquisa}

No levantamento realizado entre os meses de agosto de 2017 e dezembro de 2018, foram localizadas apenas seis dissertações de mestrado sobre o tema "tecnologia no ensino da língua inglesa", publicadas entre os anos de 2008 e 2018, conforme apresentado no Quadro 2: 
Quadro 2: Pesquisas selecionadas para análise.

\begin{tabular}{|c|c|c|c|c|}
\hline Autor & Título & $\begin{array}{l}\text { Programa de Pós- } \\
\text { Graduação }\end{array}$ & $\begin{array}{l}\text { Linha de } \\
\text { pesquisa }\end{array}$ & Tipo \\
\hline $\begin{array}{l}\text { Sobrinho } \\
\text { (2008) }\end{array}$ & $\begin{array}{l}\text { Avaliação de objetos } \\
\text { de aprendizagem } \\
\text { para o ensino da } \\
\text { língua inglesa: um } \\
\text { estudo de caso }\end{array}$ & $\begin{array}{l}\text { Programa de Pós- } \\
\text { Graduação em } \\
\text { Engenharia Elétrica } \\
\text { da Universidade } \\
\text { Federal do Pará }\end{array}$ & - & Mestrado \\
\hline $\begin{array}{l}\text { Duarte } \\
(2010)\end{array}$ & $\begin{array}{l}\text { Motivação e } \\
\text { autonomia no ensino } \\
\text { e aprendizagem da } \\
\text { habilidade da escrita } \\
\text { em inglês como } \\
\text { língua estrangeira: os } \\
\text { gêneros textuais do } \\
\text { Orkut e as suas } \\
\text { interfaces } \\
\text { interacionais }\end{array}$ & $\begin{array}{l}\text { Programa de Pós- } \\
\text { Graduação em } \\
\text { Letras da } \\
\text { Universidade } \\
\text { Federal do Pará }\end{array}$ & $\begin{array}{c}\text { Ensino e } \\
\text { Aprendizagem } \\
\text { de } \\
\text { Línguas }\end{array}$ & Mestrado \\
\hline Lima (2016) & $\begin{array}{l}\text { Os desafios do ensino } \\
\text { de inglês para fins } \\
\text { específicos à } \\
\text { distância: um estudo } \\
\text { de caso. }\end{array}$ & $\begin{array}{l}\text { Programa de Pós- } \\
\text { Graduação em } \\
\text { Letras da } \\
\text { Universidade } \\
\text { Federal de } \\
\text { Rondônia }\end{array}$ & $\begin{array}{l}\text { Estudos } \\
\text { descritivos e } \\
\text { aplicados de } \\
\text { Línguas e } \\
\text { Linguagens }\end{array}$ & Mestrado \\
\hline $\begin{array}{l}\text { Lobato } \\
\text { (2016) }\end{array}$ & $\begin{array}{l}\text { Tecnologia e língua } \\
\text { inglesa: reflexões } \\
\text { sobre o uso das } \\
\text { tecnologias da } \\
\text { informação e } \\
\text { comunicação no } \\
\text { contexto escolar } \\
\text { amazônico }\end{array}$ & $\begin{array}{l}\text { Programa de Pós- } \\
\text { Graduação em } \\
\text { Letras da } \\
\text { Universidade } \\
\text { Federal de } \\
\text { Rondônia }\end{array}$ & $\begin{array}{l}\text { Estudos } \\
\text { descritivos e } \\
\text { aplicados de } \\
\text { Línguas e } \\
\text { Linguagens }\end{array}$ & Mestrado \\
\hline $\begin{array}{l}\text { Alencar } \\
(2017)\end{array}$ & $\begin{array}{l}\text { A sala de aula de } \\
\text { línguas estrangeiras } \\
\text { em cursos técnicos a } \\
\text { distância como um } \\
\text { sistema adaptativo } \\
\text { complexo: } \\
\text { contribuições e } \\
\text { limitações. }\end{array}$ & $\begin{array}{l}\text { Programa de Pós- } \\
\text { Graduação em } \\
\text { Letras da } \\
\text { Universidade } \\
\text { Federal do } \\
\text { Tocantins }\end{array}$ & $\begin{array}{l}\text { Linguística } \\
\text { Aplicada }\end{array}$ & Mestrado \\
\hline $\begin{array}{l}\text { Almeida } \\
\text { (2018) }\end{array}$ & $\begin{array}{l}\text { Possibilidades } \\
\text { pedagógicas do } \\
\text { aplicativo WhatsApp } \\
\text { em um curso de } \\
\text { Letras Inglês: } \\
\text { sentidos construídos } \\
\text { durante uma } \\
\text { experiência de ensino } \\
\text { da língua inglesa }\end{array}$ & $\begin{array}{l}\text { Programa de Pós- } \\
\text { Graduação em } \\
\text { Letras da } \\
\text { Universidade } \\
\text { Federal do Acre }\end{array}$ & $\begin{array}{l}\text { Língua(gens) e } \\
\text { Formação } \\
\text { Docente }\end{array}$ & Mestrado \\
\hline
\end{tabular}

Fonte: elaborado pelas autoras. 
Cada um dos trabalhos aborda o tema sob uma ótica distinta e particular. Sobrinho (2008) analisa a usabilidade de quatro objetos de aprendizagem $(\mathrm{OA})^{1}$ em quatro escolas da cidade de Santarém - Pará; Duarte (2010) discute sobre o emprego de gêneros textuais da plataforma digital Orkut $^{2}$ em suas aulas na Universidade Federal do Pará campus Bragança; Lima (2016) realiza uma investigação sobre o ensino de inglês instrumental no contexto a distância, em cursos técnicos, numa escola pública na cidade de Porto Velho - Rondônia; Lobato (2016) reflete sobre o uso de recursos tecnológicos em cinco escolas públicas no município de Humaitá - Amazonas; Alencar (2017) investiga as contribuições e limitações do ambiente virtual de aprendizagem (AVA) Moodle ${ }^{3}$ no ensino de línguas estrangeiras em um curso técnico a distância de uma instituição federal em Palmas - Tocantins; e Almeida (2018) explora as possibilidades pedagógicas do uso do aplicativo WhatsApp ${ }^{4}$ em aulas ministradas aos graduandos em Letras da Universidade Federal do Acre, campus Floresta, na cidade de Cruzeiro do Sul. Apesar da singularidade de cada pesquisa, os trabalhos têm o traço comum de serem estudos que apresentam resultados positivos sobre o uso de ferramentas digitais nas aulas de língua inglesa.

\subsection{Objetivos das dissertações}

Os estudos elencados visam apresentar soluções para os desafios observados em seus respectivos contextos regionais e educacionais. Todos, em unanimidade, encontram nas ferramentas digitais respostas para os problemas levantados.

Sobrinho (2008), em sua pesquisa "Avaliação de objetos de aprendizagem para o ensino da língua inglesa: um estudo de caso", explicou que o interesse pelo tema surgiu da constatação de uma carência de recursos pedagógicos e de profissionais habilitados a lecionar a disciplina nas escolas de Santarém (p. 15). A partir disso, a autora propôs como objetivo do trabalho avaliar quatro OAs produzidos para o ensino de Inglês, averiguando sua real potencialidade como material de suporte para professores e estudantes. Segundo ela, "o uso dos OA é de fundamental importância para auxiliar o professor e proporcionar aos estudantes um aprendizado de qualidade, ou pelo menos minimizar suas dúvidas e dificuldades e proporcionar-Ihes interesse pela disciplina". (SOBRINHO, 2008, p. 16).

Duarte (2010), em seu estudo "Motivação e autonomia no ensino e aprendizagem

1 Segundo Leffa (2006), o conceito dominante de objeto de aprendizagem é "qualquer arquivo digital (texto, imagem, ou vídeo), desde que usado para facilitar e promover a aprendizagem." (LEFFA, 2006, p. 7).

2 Segundo informações do site Wikipédia, o Orkut foi uma rede social filiada à multinacional Google, criada em janeiro de 2004 e desativada em setembro de 2014.

3 O Moodle é uma sala de aula virtual onde as aulas são ministradas, onde professores e alunos postam atividades, conteúdos, interagem entre si por meio dos chats e fóruns, além de outros recursos. Todos possuem identificação e senha por meio das quais acessam essa sala de aula a partir de qualquer computador conectado à internet (ALENCAR, 2017, p. 3).

4 O software WhatsApp é um aplicativo gratuito que surgiu em 2009 como uma opção ao sistema SMS (serviço de mensagens curtas) e, seu nome, segundo o site oficial, surgiu a partir de um trocadilho com a expressão "What's up" da língua Inglesa que em português significa "o que se passa", "quais as novidades" (ALMEIDA, 2015, apud ALMEIDA, 2018, p. 70). 
da habilidade da escrita em inglês como língua estrangeira: os gêneros textuais do Orkut e as suas interfaces interacionais", atentou para a falta de motivação de seus alunos de inglês em relação à prática da habilidade de escrita. Ao que tudo indicava, essa prática só acontecia no ambiente de sala de aula, quando requisitado pelo professor. Assim, nas palavras do autor,

O objetivo primeiro deste trabalho foi analisar até que ponto a motivação e a autonomia dos estudantes de língua inglesa poderiam ser fomentadas a partir do uso de recursos virtuais dispostos na Internet, mais especificamente, dos gêneros textuais albergados em softwares de interação on-line (DUARTE, 2010, p. 108).

Lima (2016), em sua pesquisa "Os desafios do ensino de inglês para fins específicos à distância: um estudo de caso", destacou a necessidade de democratização do ensino, utilizando modalidades alternativas à aula presencial. O autor ressalta que uma das grandes contribuições das novas tecnologias ao processo educacional é o encurtamento das distâncias, promovendo acessibilidade ao ensino de qualidade. Segundo Lima (2016, p. 110), tal fato atenderia, em especial, às necessidades observadas em sua localidade, o estado de Rondônia. Portanto, o objetivo de seu trabalho é "otimizar o ensino da língua inglesa a distância e investigar as percepções das professoras de inglês instrumental sobre o ensino-aprendizagem dessa língua nessa modalidade" (p. 6).

Lobato (2016), no seu estudo sobre "Tecnologia e língua inglesa: reflexões sobre o uso das tecnologias da informação e comunicação no contexto escolar amazônico", destacou a incoerência entre o atual contexto tecnológico e a não utilização, ou subutilização, de recursos digitais nas escolas. Diante disso, o objetivo de sua pesquisa foi "investigar, junto às escolas estaduais do município de Humaitá, o uso das Novas Tecnologias nas aulas de Língua Inglesa" e verificar "como a comunidade escolar tem-se comportado diante dos aparatos tecnológicos que a escola dispõe ou deixa de dispor para uso didático/pedagógico" (p. 16).

Alencar (2017), em sua pesquisa "A sala de aula de línguas estrangeiras em cursos técnicos a distância como um sistema adaptativo complexo: contribuições e limitações", buscou compreender como as línguas estrangeiras (LEs) são ensinadas em cursos na modalidade a distância de forma que os alunos sejam capacitados a atuar criticamente como profissionais em uma sociedade digital e globalizada (p. 6). Para isso, a autora analisou aulas de línguas ministradas na plataforma Moodle. Alencar baseia-se nos conceitos de sistemas adaptativos $\operatorname{complexos}^{5}$ e de multiletramentos ${ }^{6}$ para avaliação da efetividade das aulas. Diz ela:

5 Alencar relaciona o ensino de línguas estrangeiras com sistemas adaptativos complexos. "A sala de aula de línguas é compreendida como um sistema adaptativo complexo [...] Em um SAC, agentes individuais interagem entre si e adaptam-se uns aos outros e ao ambiente." (NELSON, 2004, apud ALENCAR, 2017, p. 38).

6 A autora pauta-se no conceito de multiletramentos, exigido em ambientes digitais. "No ambiente digital [...] Um texto pode estar representado por meio de imagens, sons, vídeos, hyperlinks, entre outros, além da própria escrita em diferentes layouts. Aprender a ler e escrever no meio digital também requer novos letramentos, ou multiletramentos quando pensamos em letramentos que englobam tanto a multimodalidade dos textos digitais quanto a multiculturalidade da sociedade atual [...]" (ALENCAR, 2017, p. 1). 
Partindo do pressuposto de que as salas de aula on-line de LEs são sistemas adaptativos complexos, o presente estudo tem como objetivo geral identificar as contribuições e as limitações do ensino de LEs em cursos técnicos na modalidade a distância, considerando-se o desenvolvimento dos multiletramentos (ALENCAR, 2017, p. 6).

Almeida (2018), em sua pesquisa "Possibilidades pedagógicas do aplicativo WhatsApp em um curso de Letras Inglês: sentidos construídos durante uma experiência de ensino da língua inglesa", refletiu sobre o fato de que as novas tecnologias (em especial, os dispositivos móveis) não costumam ser utilizadas de forma estratégica pelos professores, que insistem em mantê-las fora da sala de aula, apesar destas se proliferarem a cada dia e estarem intensamente presentes no cotidiano dos estudantes. Diante dos desafios desse contexto tecnológico, o autor optou por avaliar as potencialidades do aplicativo ${ }^{7}$ WhatsApp em favor de uma aprendizagem mais participativa e integrada. Ele apresenta como objetivos de seu estudo,

avaliar as possibilidades pedagógicas do aplicativo WhatsApp durante uma experiência de ensino da língua inglesa [...] a hipótese é que ele (aplicativo) poderia oferecer ao educador a possibilidade de associá-lo à práticas de ensino coesas, podendo promover e enriquecer tanto a prática pedagógica quanto a construção de conhecimento dos sujeitos envolvidos em ambiente colaborativo (ALMEIDA, 2018, p. 22).

\subsection{Metodologias utilizadas nas dissertações}

A metodologia predominante foi o estudo de caso, apenas um estudo utilizou a pesquisa-ação. Para coleta de dados, cinco dos seis pesquisadores aplicaram questionários a grupos específicos de professores e/ou alunos.

Sobrinho (2008) desenvolveu sua pesquisa em três escolas públicas e em uma escola privada da cidade de Santarém, Oeste do Pará. A autora distribuiu questionários a 300 estudantes do $6^{\circ}$ ano do Ensino Fundamental e a seus professores de inglês com 0 objetivo de avaliar a usabilidade e a efetividade dos quatro OAs produzidos por ela, em parceria entre Paula Christina Figueira Cardoso e Marialina Corrêa Sobrinho (SOBRINHO, 2008, p. 18). Posteriormente, fez um estudo estatístico dos dados coletados.

Duarte (2010) realizou uma pesquisa-ação ${ }^{8}$ com seus 24 alunos de graduação em Letras, habilitação em Língua Inglesa, da Universidade Federal do Pará, campus Bragança. O autor utilizou questionários para verificar as principais necessidades dos estudantes em relação às habilidades de escrita em inglês. Além disso, ele analisou os registros das aulas e as produções textuais feitas na plataforma Orkut, principalmente, as

7 O software WhatsApp é um aplicativo gratuito que surgiu em 2009 como uma opção ao sistema SMS (serviço de mensagens curtas) e, seu nome, segundo o site oficial, surgiu a partir de um trocadilho com a expressão "What's up" da língua Inglesa que em português significa "o que se passa", "quais as novidades." (ALMEIDA, 2015, apud ALMEIDA, 2018, p. 70).

8 Duarte conceitua pesquisa-ação como um tipo de investigação em que "o professor-pesquisador, ao detectar questões que comprometem negativamente o desenvolvimento das suas práticas de ensino, lança-se na elaboração de projetos que têm como foco de interesse a busca por soluções e mudanças possíveis para o quadro pedagógico que ele julga insatisfatório." (DUARTE, 2010, p. 69). 
realizadas após o término da disciplina.

Lima (2016) aplicou questionários a três professoras da disciplina de Inglês Instrumental (na modalidade a distância) de uma escola pública da cidade de Porto Velho, Rondônia. Além dos questionários sobre a atuação docente no ensino à distância, o autor realizou observações e análises das aulas ministradas.

Lobato (2016) realizou a pesquisa com cinco professores da rede pública estadual de cinco escolas diferentes, do município de Humaitá, no Amazonas. Eles responderam a um questionário com perguntas que visavam verificar como a comunidade escolar tem se comportado diante dos recursos tecnológicos de que dispõe para uso didático/pedagógico.

Alencar (2017) investigou as aulas de Inglês Aplicado, ministradas a 170 alunos do curso técnico de Secretariado de uma instituição federal em Palmas, Tocantins. Para análise das aulas, a autora baseou-se em documentos institucionais referentes ao conteúdo da matéria e em documentos regulamentadores para a Educação Profissional Técnica de nível médio. Por fim, foram realizadas entrevistas com o tutor e o professor responsável pela disciplina.

Finalmente, Almeida (2018) reuniu, em um primeiro momento, publicações científicas sobre o uso do aplicativo WhatsApp em sala de aula. Após esse mapeamento, o autor planejou as aulas e estabeleceu os procedimentos de seu estudo. Foram aplicados questionários de sondagem aos 23 alunos do sétimo período do Curso de Letras Língua Inglesa da Universidade Federal do Acre, campus Floresta. Após isto, foram desenvolvidas atividades na plataforma do aplicativo que funcionavam como extensão das aulas ministradas presencialmente. Das atividades empregadas, foram selecionadas quatro produções principais para exposição e análise.

\subsection{Resultados das dissertações}

Após a aplicação dos questionários, entrevistas e a realização de análises quantitativas e qualitativas, os pesquisadores identificaram resultados positivos em relação às ferramentas digitais empregadas. Além disso, as pesquisas atestaram a centralidade do papel do professor nesse processo de ensino-aprendizagem de línguas por meio das novas tecnologias.

Sobrinho (2008) desenvolveu quatro modelos de objetos aprendizagem: Colors, Numbers, Demonstrative Pronoums e Verb To Be. Os resultados obtidos demonstram que os OAs melhoraram significativamente o ensino da Língua Inglesa nos contextos escolares em que foram utilizados. O estudo estatístico realizado por ela, após a utilização dos OAs, indicou que o aproveitamento dos alunos nas provas teve um aumento de mais de $40 \%$ (p. 77). Diante disso, a autora conclui que os OAs podem auxiliar os professores, oferecendo um suporte significativo às aulas de inglês. Sobrinho (2008, p. 79) entende que o OA atua como "coadjuvante" no processo de ensinoaprendizagem, enquanto o professor exerce o papel de mediador desse processo.

Trabalhando especificamente com o gênero textual scrap, na plataforma Orkut, Duarte (2010) constatou que, mesmo após o término da disciplina, pelos menos $50 \%$ dos alunos passaram a incorporar a escrita em inglês em sua prática diária. Após o período de aula, segundo Duarte (2010, p. 101), 15 dos 24 alunos que compunham a turma, 
continuaram a postar scraps em inglês uns para os outros com alguma frequência. $\mathrm{O}$ autor também constatou outros traços de motivação e autonomia por parte dos estudantes, destacando iniciativas como o compartilhamento de músicas, poesias, pensamentos filosóficos e frases de apresentação, em língua inglesa, em seus perfis. Assim, o autor conclui:

Podemos perceber então que, a partir do trabalho com os tipos de atividades online realizados nesta pesquisa, os alunos começaram a despertar o interesse em outros gêneros virtuais dispostos na Internet, usando-os como ferramentas que podem favorecer a prática de suas habilidades da língua que estão aprendendo. (DUARTE, 2010, p. 107).

Segundo Lima (2016, p. 111), os resultados demonstraram que as professoras conseguiram superar alguns dos desafios do ensino à distância, ainda que, muitas vezes, de maneira intuitiva. A experiência com o ensino à distância provocou novas percepções nas docentes, fazendo com que repensassem suas próprias práxis. Lima $(2016$, p. 44), citando Freire (1996, p. 25), reitera que "quando se une a prática com a teoria tem-se a práxis, a ação criadora e modificadora da realidade". Apesar disso, o autor conclui que, mesmo que os professores reconheçam as vantagens das novas tecnologias no ensino, essas ainda provocam certa resistência e insegurança nos docentes. Portanto, seria imprescindível o investimento em formação continuada de professores para minimizar essas dificuldades e ampliar as potencialidades da educação à distância.

Lobato (2016) observou que o uso adequado das ferramentas tecnológicas pode produzir mudanças positivas no ambiente escolar. No entanto, o emprego de novas tecnologias não resolve os problemas da sala de aula, apenas contribuem para sua melhoria, se forem empregadas de maneira efetiva. Isso posto, o autor reforça a necessidade de se investir em capacitação para que os professores saibam lidar com as vantagens e os problemas da nova era digital. Assim, Lobato pondera:

Com os resultados obtidos nessa pesquisa, pude concluir, principalmente, que o uso da tecnologia é de suma importância para o processo de ensino/aprendizagem de línguas, no entanto, o que se necessita com maior urgência é capacitar os usuários para bem utilizarem os equipamentos tecnológicos em suas salas (LOBATO, 2016, p. 73).

Sobre o uso de ambientes virtuais de aprendizagem (AVA) no ensino línguas, Alencar (2017) constatou que as salas de aula online, por serem sistemas adaptativos complexos, apresentam diversas vantagens devido à flexibilização do tempo e do espaço de aprendizado. Conforme destaca, tal modalidade de ensino "alcança locais onde não há instituições educacionais para o ensino presencial" (ALENCAR, 2017, p. 123). Além disso, ambientes como o Moodle permitem a utilização de diversos tipos de materiais (textuais e audiovisuais), o que contribui para o multiletramento e para o desenvolvimento das quatro habilidades (leitura, escrita, audição e fala). Porém, conforme salientado pela autora, para que haja verdadeiro proveito nas aulas em ambiente virtual, é necessária uma ruptura com o paradigma de "transmissão do conhecimento", em que o professor é detentor da informação e os alunos são meros receptores. O contexto atual demanda um modelo de ensino mais colaborativo, no qual os alunos têm mais autonomia e o professor atua como 
mediador do processo. Nas aulas analisadas, Alencar observou que a falta de preparo dos professores e alunos para o ambiente virtual acarretou baixa adesão e participação dos estudantes. Segundo relatos das entrevistas, "não havia interação nem colaboração" e "os próprios professores e tutores reclamaram dessa necessidade de se ter um contato maior com os alunos" (p. 129). Assim, a autora conclui que

\begin{abstract}
Apesar da importância e das facilidades do ensino a distância quanto à flexibilidade de tempo e espaço para estudo, ainda há problemas quanto ao uso das tecnologias, tanto relativos ao conhecimento técnico quanto ao aproveitamento do que já está disponibilizado a fim de tornar um AVA um ambiente interativo e colaborativo (ALENCAR, 2017, p. 131).
\end{abstract}

Almeida (2018) apresentou um notável engajamento nas atividades desenvolvidas através do aplicativo WhatsApp. Os alunos produziram textos, discutiram tópicos gramaticais abordados em sala de aula, elaboraram áudios e, por fim, produziram um vídeo. Conforme expõe Almeida, "na minha caminhada de professor de LI nunca tinha visto uma participação tão ativa, tantos alunos motivados, 'se digladiando', interagindo e colaborando sobre um tema de aula". O autor destaca a importância da mediação e do preparo do professor para a obtenção de tal engajamento por parte dos estudantes, assim, destaca que "foi necessário um bom planejamento, definir critérios, inclusive de conduta no grupo, e assumir, conforme Moran (2013), uma postura de mediador" (p. 112). Almeida conclui

\footnotetext{
Desta forma, as discussões possibilitadas durante a navegação mostraram que o aplicativo WhatsApp oferece efeitos benéficos para os atuais processos de ensino e aprendizagem, pois estimulou e proporcionou produções, ações e compartilhamentos colaborativos de conhecimentos e informações para além da sala de aula." (ALMEIDA, 2018, p. 136).
}

Os estudos apresentados discutem os desafios do ensino no atual contexto tecnológico e apontam para as potencialidades desses novos recursos. Os resultados alcançados e as conclusões obtidas por meio dessas pesquisas atestam a relevância do uso das novas tecnologias no ensino da língua inglesa e ressaltam a importância do professor nesse processo e, portanto, a imprescindibilidade de investimentos em capacitação desses profissionais.

\title{
3.4 Conclusão dos estudos
}

Sobrinho (2008) chama a atenção sobre a carência de recursos pedagógicos e de profissionais com habilitação em inglês em sua região. Ele constatou que a utilização de objetos de aprendizagem pode aumentar consideravelmente 0 desempenho e 0 aproveitamento dos alunos nas aulas de inglês.

Duarte (2010) encontrou nas redes sociais, como o Orkut, uma oportunidade para motivar os alunos a exercitar suas habilidades de escrita em inglês e, assim, diminuir a dependência dos exercícios e atividades propostas pelo professor em sala de aula.

Lima (2016) apontou as potencialidades da educação à distância para a 
democratização do ensino de inglês e Lobato (2016) refletiu sobre os benefícios do uso de novas tecnologias no processo de ensino-aprendizagem de inglês e a eminente necessidade de se ajustar o descompasso entre o atual contexto tecnológico e as salas de aula.

Alencar (2017) ressaltou as contribuições dos ambientes virtuais de aprendizagem ao ensino de línguas. A autora destacou a necessidade de uma mudança de paradigma na educação e de capacitação de professores e alunos para o uso dos AVA de maneira mais efetiva, de forma que se construa um ambiente colaborativo e de interação entre os participantes.

Almeida (2018), por sua vez, descobriu que, com o devido preparo e planejamento, é possível utilizar os dispositivos móveis de forma estratégica nas aulas de inglês, a fim de se obter engajamento e colaboração dos alunos.

Apesar de termos encontrado apenas seis dissertações, ficou evidente, em todos os estudos, a importância do uso de ferramentas digitais para o ensino de inglês e a necessidade de mais investimentos na formação de professores para o uso da tecnologia.

\section{Considerações finais}

Esta metapesquisa demonstrou que os estudos sobre o uso de ferramentas digitais no ensino de língua inglesa, apesar de poucos, revelam-se profícuos, apresentando análises e resultados relevantes para a comunidade científica. Todos os autores trouxeram experiências muito positivas sobre a utilização das novas tecnologias nas aulas de língua inglesa.

A Região Norte do Brasil, a despeito de sua diversidade e de grande riqueza natural e sociocultural, é uma das regiões de menor investimento no campo científicoeducacional. Diante dos altos investimentos empregados na exploração de seus recursos naturais, há, ainda, uma grande disparidade em relação aos investimentos direcionados à ciência e a educação.

Ficou evidente que é necessário mais investimento nos programas de pósgraduação dessa localidade e na formação de professor para uso de tecnologia digital. Seria interessante que os programas investissem mais em estudos em linguagem e tecnologia para o ensino de língua inglesa, tendo em vista que o ensino de inglês é obrigatório e estratégico para o consumo de conhecimentos e para a sua divulgação. Conhecer mais o potencial das tecnologias digitais pode ampliar as oportunidades de aprendizagem e de uso do idioma

O levantamento realizado para a composição do presente estudo revelou algumas limitações para a pesquisa sobre os trabalhos produzidos na Região Norte do Brasil. Inicialmente, a proposta envolvia a busca de informações sobre pesquisas em linguagem e tecnologia realizadas nos últimos cinco anos, no entanto, para abarcar uma quantidade mais relevante de trabalhos, ampliamos a proposta para os últimos 10 anos. Ainda assim, foram encontradas apenas seis dissertações e nenhuma tese sobre o tema "tecnologia no ensino da língua inglesa", indicando uma evidente disparidade entre o número de pesquisas nessa localidade e nas demais regiões do país. Diante disso, faz-se necessário pontuar que a desatualização de algumas páginas dos programas de pós-graduação e o 
parco número de trabalhos finais encontrados e analisados acabam por comprometer a abrangência das conclusões aqui apresentadas.

O Brasil ainda apresenta uma diversidade de contextos regionais e grandes disparidades socioeducacionais. Diante disso, ressaltamos a relevância de projetos como o Lalintec que, além de criar um ecossistema de produção e divulgação de pesquisas em linguagem e tecnologia, também reflete sobre as especificidades e sobre a pluralidade do contexto científico-educacional brasileiro.

Agradecimentos: agradecemos ao Conselho Nacional de Desenvolvimento Científico e Tecnológico e à Fundação de Amparo à Pesquisa do Estado de Minas Gerais pelo apoio à pesquisa.

\section{Referências}

ALENCAR, L. das G. B. A sala de aula de línguas estrangeiras em cursos técnicos a distância como um sistema adaptativo complexo: contribuições e limitações. 2017. 160 f. Dissertação (Mestrado em Linguística Aplicada). Universidade Federal do Tocantins, Porto Nacional, 2017.

ALMEIDA, G. J. de. Emprego do Aplicativo WhatsApp no Ensino de Química. 2015. 72 f. TCC (Graduação) - Curso de Química, Instituto de Química, Universidade de Brasília, Brasília, 2015. Disponível em: http:bdm.unb.br/handle/10483/11240. Acesso em: 10 nov. 2018.

ALMEIDA, J. I. M. de. Possibilidades pedagógicas do aplicativo WhatsApp em um curso de Letras Inglês: sentidos construídos durante uma experiência de ensino de língua inglesa. 2018. 150 f. Dissertação (Mestrado em Linguagem e Identidade). Universidade Federal do Acre, Rio Branco, 2018.

BENTO, M. A. S.; COELhO, W. N. B.; COELHO, M. C.; FERNANDES, D. M. P. A educação na região norte: apontamentos iniciais. Amazônica: Revista de Antropologia (Online), v. 5, p. 140-175, 2013.

BRASIL. Ministério da Educação. Coordenação de Aperfeiçoamento de Pessoal de Nível Superior. Diretoria de Avaliação. Avaliação Quadrienal 2017 - Documento de Área Letras e Linguística, Brasília, DF: CAPES, 2017. https://capes.gov.br/images/documentos/Documentos_de_area_2017/41_LETR_docarea 2016.pdf. Acesso em: 05 maio 2018.

Coordenação de Aperfeiçoamento de Pessoal de Nível Superior (CAPES). Avaliação da CAPES aponta crescimento da pós-graduação brasileira, 2017a. Disponível em: http://www.capes.gov.br/sala-de-imprensa/noticias/8558-avaliacao-da-capes-apontacrescimento-da-pos-graduacao-brasileira. Acesso em: 05 maio 2018.

Coordenação de Aperfeiçoamento de Pessoal de Nível Superior (CAPES). Documento de 
Área - Letras e Linguística. 2017b. Disponível em: https://capes.gov.br/images/documentos/Documentos_de_area_2017/41_LETR_docarea_ 2016.pdf. Acesso em: 05 maio 2018.

DUARTE, F. E. B. Motivação e autonomia no ensino e aprendizagem da habilidade da escrita em inglês como língua estrangeira: os gêneros textuais do Orkut e as suas interfaces interacionais. 2010. 124 f. Dissertação (Mestrado em Estudos Linguísticos) Instituto de Letras e Comunicação, Universidade Federal do Pará, Belém, 2010.

FREIRE, P. Pedagogia da Autonomia: saberes necessários à prática educativa. São Paulo: Paz e Terra, 1996.

Instituto Brasileiro de Geografia e Estatística (IBGE). Área dos municípios. Disponível em: https://ww2.ibge.gov.br/home/geociencias/cartografia/default_territ_area.shtm. Acesso em: 05 maio 2018.

Instituto Brasileiro de Geografia e Estatística (IBGE). Cidades e estados do Brasil. Disponível em: https://cidades.ibge.gov.brl. Acesso em: 05 maio 2018.

LEFFA, V. J. Nem tudo que balança cai: objetos de aprendizagem no ensino de línguas. Polifonia. Cuiabá, v. 12, n. 2, p. 15-45, 2006.

LIMA, M. L. Os desafios do ensino de inglês para fins específicos à distância: um estudo de caso. 2016. 127 f. Dissertação (Mestrado em Letras) - Faculdade de Letras, Universidade Federal de Rondônia, Porto Velho, 2016.

LOBATO, C. P. Tecnologia e língua inglesa: Reflexões sobre o uso das tecnologias da informação e comunicação no contexto escolar amazônico. 2016. 85 f. Dissertação (Mestrado em Letras) - Faculdade de Letras, Universidade Federal de Rondônia, Porto Velho, 2016.

NONATO, J. M. S.; PEREIRA, N. M. Histórico da ciência na Região Norte do Brasil: A ciência em ação na Amazônia brasileira. Perspectivas. São Paulo, v. 44, p. 93-124, jul./dez. 2013.

PERRY, Jr., Fred L. Research in Applied Linguistics: becoming a discerning consumer. 3a ed. London, New York. Routledge, 2017.

PROGRAMA DE PÓS-GRADUAÇÃO EM LETRAS E ARTES. Universidade Estadual do Amazonas. Disponível em: http://www.pos.uea.edu.br/data/area/apresent/download/61.pdf. Acesso em: 02 ago. 2018.

PROGRAMA DE PÓS-GRADUAÇÃO EM LETRAS. Universidade Federal de Tocantins. Histórico. Disponível em: http://ww2.uft.edu.br/index.php/ppgletras/historico. Acesso em: 02 ago. 2018.

SOBRINHO, M. C. Avaliação de objetos de aprendizagem para o ensino da língua 
inglesa: um estudo de caso. 2008. Dissertação de Mestrado. Universidade Federal do Pará - UFPA. Belém.

TROCHIM, W. M.; DONNELLY, J. P. Research Methods: The Essential Knowledge Base, Second Edition. Boston, MA.: Cengage Learning, 2016.

WALLIMAN, N. Research methods: the basics. New York: Routledge, 2011.

WIKIPÉDIA. Orkut. Disponível em: https://pt.wikipedia.org/wiki/Orkut. Acesso em: 05 maio 2018.

Recebido em dia 14 de janeiro de 2019. Aprovado em dia 18 de fevereiro de 2019. 